\title{
Дослідження ефективності використання додаткового обладнання у підготовчому періоді річного макроциклу спортсменів-пауерліфтерів високої кваліфікації
}

\author{
Богдан Семко \\ Вадим Воронецький \\ Віктор Джим ${ }^{1}$
}

\author{
Харківська державна академія фізичної культури, Харків, Україна' \\ Кам'янець-Подільський національний університет імені Івана Огієнка, \\ Кам'янець-Подільський, Україна
}

\begin{abstract}
Мета: дослідити вплив застосування додаткового обладнання, а саме гумових еспандерів, на розвиток силових показників пауерліфтерів високої кваліфікації.

Матеріал і методи: до дослідження було залучено 20 пауерліфтерів високої кваліфікації.

Результати: встановлено, що використання додаткового обладнання в пауерліфтингу сприяє більш ефективному розвитку силових якостей спортсменів, а, отже, веде до зростання спортивних результатів у присіданні, жимі лежачи та тязі. Використання додаткового обладнання дає можливість виконувати вправи з використанням гумових еспандерів. Гумові еспандери фіксуються в силовій рамі зверху, після чого розтягуються та кріпляться до штанги, за рахунок розтягнення еспандерів спортсмен має можливість полегшити підйом в нижній точці. Допомога еспандерів в нижній точці найбільша, а в верхній точці відсутня. Дані вправи рекомендовано атлетам високої кваліфікації, при їх використанні необхідно чітко слідкувати за технікою виконання вправ, тому що в останніх фазах вправ спостерігається м'язова втома і техніка виконання вправи часто порушується. Спортсмени експериментальної групи використовували вправи з гумовим еспандером у підготовчий період з розвитку силових якостей у змагальних вправах: присідання зі штангою, жимі лежачи, тязі. За період підготовки виконали 768 підйомів штанги в присіданнях, що дорівнює 169 тисяч кілограм, 1020 підйомів штанги в жимі лежачи, що дорівнює 141 тисяч кілограм, 720 підйомів у тязі, що дорівнює 165 тисяч кілограм. За період дослідження контрольна й експериментальна групи збільшили показники: у присіданнях зі штангою (контрольна - 10 кг, експериментальна - 15 кг; $t=2,82 ; P<0,05)$; жимі лежачи (відповідно - 5 кг, 10 кг; $t=1,81 ; P>0,05) ;$ станова тяга (відповідно - 5 кг, 15 кг; $t=1,63$ P>0,05), що дає більш суттєве підвищення результату експериментальної групи щодо контрольної.
\end{abstract}

Висновки: встановлено, що використання даного методу сприяє більш ефективному розвитку силових показників, а, отже, веде до зростання спортивних результатів у всіх трьох дисциплінах пауерліфтингу.

Ключові слова: пауерліфтинг, додаткове обладнання, присідання, гумовий еспандер.

\section{Вступ}

Сучасна система підготовки потребує постійного вдосконалення методик для підвищення силових показників спортсменів силових видів спорту. Як показує аналіз спеціальної літератури, при силовій підготовці пауерліфтерів, в основному, використовуються методичні підходи і прийоми, випробувані у важкій атлетиці $[2,3]$. У річних макроциклах на всіх етапах підготовки пауерліфтерів використовують статичні, динамічні та змішані режими роботи, оскільки дані режими є класичними для підготовки спортсменів силових видів спорту [7].

На теперішній час технічне забезпечення дозволяє 3 успіхом застосовувати нетрадиційні методи розвитку силових якостей, одним з яких є використання додаткового обладнання у вигляді гумових еспандерів. Даний варіант використання додаткового обладнання є актуальним для вивчення в рамках підготовки пауерліфтерів, оскільки всі класичні вправи мають фіксоване навантаження, з яким взаємодіє спортсмен, а за допомогою сучасних засобів підготовки, а саме гумових еспандерів, ми можемо змінити силу, з якою знаряд взаємодіє зі спортсменом, де зусилля, яке спортсмен прикладає, буде змінюватись, а вага буде залишатися тією самою за рахунок застосування еспандерів. Таким чином, навантаження, з яким взаємодіє спортсмен, буде змінюватись.

Аналіз науково-методичної літератури показує, що дослідження відомих вітчизняних науковців: В.Г. Олешко [6], О.Б. Півень [7] - стосувалися швидкісно-силової підготовки важкоатлетів, Л.С. Дворкін [2] досліджував розвиток силових здібностей в ізокінетичному режимі з ви- 
користанням тренажерних пристроїв. Увесь практичний досвід вказує на недостатність досліджень нетрадиційних методів розвитку силових здібностей, а особливо з використанням змінного навантаження у пауерліфтингу. Даний режим є перспективним для вивчення, що й зумовило актуальність вибраної теми дослідження.

Відомими дослідниками в сфері пауерліфтингу та силових видів спорту, В.Г. Олешко [6], А.І. Стеценко [8] було встановлено, що пауерліфтери високої кваліфікації мають високу інтенсивність, приблизно 80 - 100 \% від максимуму, і доволі високий тренувальний об'єм, що дорівнює 80-100 підйомів штанги на тиждень в базових вправах, через що підвищення силових показників за допомогою збільшення об'єму або інтенсивності не $€$ дієвим. Навіть виконання таких вимог не призводить до підвищення силових показників і $€$ небезпечним 3 боку травматизму та психологічної і фізичної перевтоми спортсмена, тому пошук нових методів та режимів $€$ важливим та актуальним.

Результатом аналізу сучасної літератури є відсутність та недостатність досліджень нетрадиційних методів розвитку силових здібностей, а особливо методу розвитку з використанням гумових еспандерів у пауерліфтингу. Даний режим є перспективним для вивчення, що й зумовило актуальність вибраної теми дослідження.

Мета дослідження - дослідити вплив застосування додаткового обладнання, а саме гумових еспандерів, на розвиток силових показників пауерліфтерів високої кваліфікації.

\section{Матеріал і методи дослідження}

Методи дослідження: відповідно до методологічного підходу у вирішенні проблеми і поставлених завдань про- грама досліджень включала комплекс методів дослідження: аналіз науково-методичної літератури, визначення спеціальної фізичної підготовленості за допомогою педагогічного тестування кваліфікованих пауерліфтерів, педагогічне дослідження та методи математичної статистики.

Організація дослідження: у даному дослідженні брали участь висококваліфіковані пауерліфтери-вихованці ДЮСШ «ХТЗ» та спортсмени, які тренуються на базіХНУБА. До експерименту були залучені 20 високо- кваліфікованих пауерліфтерів різного віку. Усі вони мали кваліфікацію МСУ або МСУМК. Учасники були розподілені на дві рівномірні групи - контрольна та експериментальна, по 10 чоловік у кожній. Всі спортсмени виступають в вагових категоріях до 93 і до 105 кілограм. Тренування проводилося 4 рази на тиждень на навчально-тренувальній базі КЗ КДЮСШ ХТЗ та ХНУБА. Тривалість експерименту 6 місяців.

\section{Результати дослідження}

Експеримент був організований за традиційною програмою тренувань пауерліфтерів для контрольної групи, експериментальна група тренувалася з використанням гумових еспандерів.

Перед експериментом усі учасники прийняли участь в контрольних змаганнях (їх результати були прийняті нами за вихідний рівень підготовленості). Період тренувань склав 6 місяців.

Контрольна група тренувалася за загальноприйнятою методикою, об'єм навантаження вказано в табл. 1. В експериментальній групі загальний об'єм роботи був несуттєво, але скорочений за рахунок більшої інтенсивності вправ з використанням гумових еспандерів для створення змінного навантаженням, об'єм навантаження вказано в табл. 1.

Таблиця 1 Об'єм навантаження контрольної та експериментальної груп за період експерименту

\begin{tabular}{|c|c|c|c|c|c|c|c|c|}
\hline \multirow[b]{2}{*}{ Вправи } & \multicolumn{2}{|c|}{ КГ } & \multicolumn{6}{|c|}{$\mathbf{E \Gamma}$} \\
\hline & 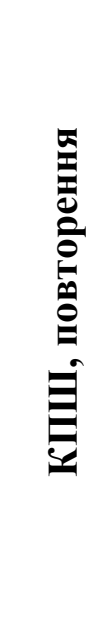 & 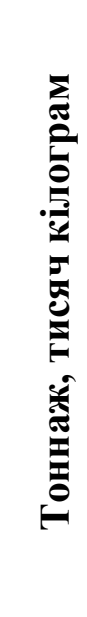 & 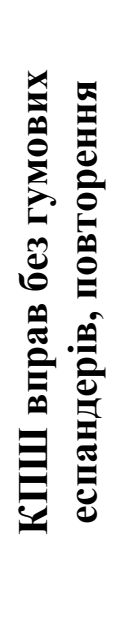 & 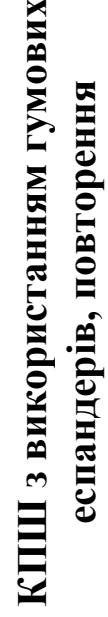 & 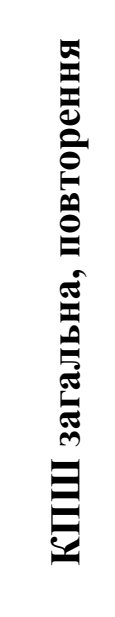 & 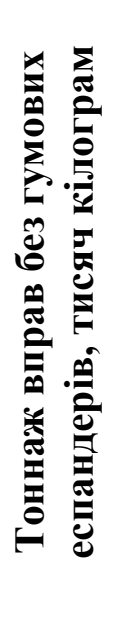 & 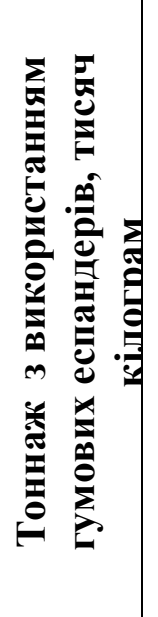 & 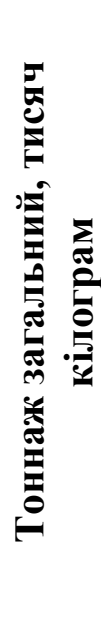 \\
\hline $\begin{array}{l}\text { Присідання зі штангою на } \\
\text { плечах }\end{array}$ & 780 & 166 & 494 & 274 & 768 & 98 & 71 & 169 \\
\hline Жим штанги лежачи & 1050 & 140 & 752 & 268 & 1020 & 85 & 62 & 147 \\
\hline Станова тяга & 740 & 162 & 436 & 284 & 720 & 95 & 70 & 165 \\
\hline
\end{tabular}


Відмінність тренувальної програми експериментальної групи була у використанні додаткового обладнання, а саме гумових еспандерів, для створення змінного навантаження. Виконання даних вправ реалізовано за допомогою гумових еспандерів, які фіксуються в силовій рамі зверху, розтягуються та кріпляться на штангу за рахунок розтягнення гумових еспандерів спортсмен має можливість полегшити підйом в нижній точці. Тобто допомога еспандеру в нижній точці буде найбільшою, а у верхній - майже відсутньою. Тому результатом використання даного обладнання $€$ можливість роботи 3 більшою вагою в діапазоні 90 - 110\% від разового максимуму, на відміну від класичних режимів, при яких основна робота здійснюється в діапазоні 70 - 90\% від разового максимуму.

Вправи з використанням еспандерів застосовувалися $з$ наступною регулярністю: у присіданнях і жимі лежачи кожний тиждень, тяга - раз у два тижні (через специфіку дозування тренувального об'єму та інтенсивності в тязі). Вправи з гумовим еспандером застосову- валися по 4 спроби з кількістю повторень у спробі в діапазоні від 4 до 1.

Основними ефектами при використанні додаткового обладнання, а саме гумових еспандерів, крім загальновідомих від силових тренувань, є більша загальна інтенсивність. Також важливим $є$ ефект роботи з більшою вагою, що зміцнює впевненість спортсмена при виконанні вправ з максимальним навантаженням.

У кінці загальнопідготовчого етапу спортсмени експериментальної групи показали більш високі результати, на відміну від контрольної, яка тренувалася за загальноприйнятою методикою. Так, на початку експерименту розходження несуттєві: у присіданнях зі штангою (контрольна - 237,5 кг, експериментальна -235 кг; $\mathrm{t}=$ 2,81; Р<0,05); у жимі лежачи (відповідно - 165 кг, 162,5 кг; $\mathrm{t}=1,84 ; \mathrm{P}>0,05)$; станова тяга (відповідно - 255 кг, 252,5 кг; t = 1,12; P>0,05) (табл. 2), (табл. 3).

Коефіцієнти варіації всіх основних показників базових вправ окремо для контрольної та експериментальної груп практично не перевищували загальний вихідний рі-

Таблиця 2

Показники результатів змагальних вправ контрольної групи на початку підготовчого періоду та в кінці $(n 1=n 2=10)$

\begin{tabular}{|l|c|c|c|c|c|c|}
\hline \multirow{2}{*}{ Показники } & \multicolumn{2}{|c|}{ На початку } & \multicolumn{2}{c|}{ В кінці } & \multirow{2}{*}{$t$} & \multirow{2}{*}{$P$} \\
\cline { 1 - 6 } & $\bar{X}_{1} \pm m_{1}$ & $V, \%$ & $\bar{X}_{1} \pm m_{1}$ & $V, \%$ & & \\
\hline Присідання зі штангою, кг & $237,5 \pm 2,5$ & 1,1 & $247,5 \pm 2,5$ & 1,0 & 2,81 & $<0,05$ \\
\hline Жим лежачи, кг & $165,0 \pm 2,5$ & 1,5 & $170,0 \pm 1,25$ & 0,7 & 1,84 & $>0,05$ \\
\hline Станова тяга, кг & $255,0 \pm 3,75$ & 1,5 & $260,0 \pm 2,5$ & 1,0 & 1,12 & $>0,05$ \\
\hline
\end{tabular}

Таблиця 3

Показники результатів змагальних вправ експериментальної групи на початку підготовчого періоду та в кінці $(\mathbf{n} 1=$ n2=10)

\begin{tabular}{|c|c|c|c|c|c|c|}
\hline \multirow{2}{*}{ Показники } & \multicolumn{2}{|c|}{ На початку } & \multicolumn{2}{|l|}{ В кінці } & \multirow{2}{*}{$t$} & \multirow{2}{*}{$P$} \\
\hline & $\bar{X}_{1} \pm m_{1}$ & $V, \%$ & $\bar{X}_{1} \pm m_{1}$ & $V, \%$ & & \\
\hline Присідання зі штангою, кг & $235,0 \pm 3,75$ & 1,6 & $250,0 \pm 3,75$ & 1,5 & 2,81 & $<0,05$ \\
\hline Жим лежачи, кг & $162,5 \pm 3,13$ & 1,9 & $172,5 \pm 2,5$ & 1,5 & 2,52 & $<0,05$ \\
\hline Станова тяга, кг & $252,5 \pm 3,75$ & 1,5 & $267,5 \pm 4,4$ & 1,6 & 2,61 & $<0,05$ \\
\hline
\end{tabular}

Таблиця 4

Показники результатів змагальних вправ експериментальної групи та контрольної групи в кінці підготовчого періоду (n1= n2=10)

\begin{tabular}{|l|c|c|c|c|c|c|}
\hline \multirow{2}{*}{\multicolumn{1}{|c|}{ Показники }} & \multicolumn{2}{|c|}{ КГ } & \multicolumn{2}{c|}{ EГ } & \multirow{2}{*}{$\boldsymbol{P}$} \\
\cline { 2 - 6 } & $\bar{X}_{1} \pm m_{1}$ & $V, \%$ & $\bar{X}_{2} \pm m_{2}$ & $V, \%$ & & \\
\hline Присідання зі штангою, кг & $247,5 \pm 2,5$ & 1,0 & $250 \pm 3,75$ & 1,5 & 0,55 & $>0,05$ \\
\hline Жим лежачи, кг & $170,0 \pm 1,25$ & 0,7 & $172,5 \pm 2,5$ & 1,5 & 0,89 & $>0,05$ \\
\hline Станова тяга, кг & $260,0 \pm 2,5$ & 1,0 & $267,5 \pm 4,4$ & 1,6 & 1,48 & $>0,05$ \\
\hline
\end{tabular}


Таблиця 5

Приріст в змагальних вправах контрольної групи та експериментальної групи в кінці підготовчого періоду $(\mathrm{n} 1=\mathrm{n} 2=10)$

\begin{tabular}{|l|c|c|c|c|c|c|}
\hline \multirow{2}{*}{\multicolumn{1}{c|}{ Показники }} & \multicolumn{2}{|c|}{ КГ } & \multicolumn{2}{|c|}{ ЕГ } & \multirow{2}{*}{$\boldsymbol{P}$} \\
\cline { 2 - 6 } & $\bar{X}_{1} \pm m_{1}$ & $V, \%$ & $\bar{X}_{2} \pm m_{2}$ & $V, \%$ & & \\
\hline Присідання зі штангою, кг & $10,0 \pm 1,25$ & 12,5 & $15,0 \pm 1,25$ & 8,3 & 2,82 & $<0,05$ \\
\hline Жим лежачи, кг & $5,0 \pm 1,25$ & 25,0 & $10,0 \pm 2,5$ & 25,0 & 1,81 & $>0,05$ \\
\hline Станова тяга, кг & $5,0 \pm 3,75$ & 75,0 & $15,0 \pm 5,0$ & 33,3 & 1,63 & $>0,05$ \\
\hline
\end{tabular}

вень. Наприклад, для присідань зі штангою контрольної групи він склав $V=1,1 \%$, для експериментальної - $V$ $=1,6 \%$. Відповідно для контрольної та експериментальної груп коефіцієнти варіації склали наступні значення: жим лежачи $V=1,5 \%, V=1,9 \%$; станової тяги - $V$ $=1,5 \%, V=1,5$.

В кінці експерименту середні показники в присіданні зі штангою склали (контрольна - 247,5 кг, експериментальна - 250 кг; t = 0,55; P>0,05); жимі лежачи (відповідно - 170 кг, 172,5 кг; t = 0,89; Р>0,05); станова тяга (відповідно - 260 кг, 267,5 кг; t = 1,48; Р >0,05) (табл. 4).

У кінці експерименту вірогідною була і різниця між показниками: у присіданнях зі штангою (контрольна - 10 $к г$, експериментальна - 15 кг; $\mathrm{t}=2,82 ; \mathrm{P}<0,05)$; жимі лежачи (відповідно - 5 кг, 10 кг; ; t = 1,81; Р >0,05); станова тяга (відповідно - 5 кг, 15 кг; t = 1,63; P>0,05) (табл. 5).

\section{Висновки/ Дискусія}

Аналіз наукової літератури підтвердив, що за останні роки вченими були проведені дослідження щодо змісту та методики тренувального процесу кваліфікованих пауерліфтерів за різними методами (Олешко В.Г., Стеценко А.І.) [6, 8]. Однак, не достатньо вивчено вплив використання гумових еспандерів у тренуваннях кваліфікованих пауерліфтерів у підготовчому періоді, що й спонукало провести аналіз у даному напрямку.
Результати педагогічного експерименту з використанням гумових еспандерів в розвитку силових якостей кваліфікованих пауерліфтерів свідчить, що використання даного методу сприяє більш ефективному розвитку силових якостей, а, отже, веде до зростання спортивних результатів у всіх трьох дисциплінах пауерліфтингу. Використання вправ з гумовими еспандерами рекомендовано атлетам тільки високої кваліфікації, адже при його застосуванні необхідно чітко слідкувати за технікою виконання вправ, у яких застосовується даний метод, адже в останніх фазах вправ спостерігається м'язова втома і техніка виконання вправи часто порушується.

При проведенні дослідження контрольна й експериментальна групи збільшили показники: у присіданнях зі штангою (контрольна - 10 кг, експериментальна - 15 кг; $\mathrm{t}=2$,82; $\mathrm{P}<0,05)$; жимі лежачи (відповідно - 5 кг, 10 кг; $\mathrm{t}$ $=1,81 ; \mathrm{P}>0,05)$; станова тяга (відповідно $-5 \mathrm{\kappa r,} 15 \mathrm{\kappa г;} \mathrm{t}=$ $1,63 ; P>0,05)$, що дає більш суттєве підвищення результату експериментальної групи щодо контрольної.

Проведене дослідження підтвердило доцільність використання додаткового обладнання, а саме гумових еспандерів, та подальшого його вивчення.

Перспективи подальших досліджень. Подальші дослідження будуть спрямовані на розробку та обґрунтування тренувального процесу кваліфікованих пауерліфтерів на етапі підготовчого періоду річного макроциклу.

Конфлікт інтересів. Автори заявляють, що відсутній конфлікт інтересів, який може сприйматись таким, що може завдати шкоди неупередженості статті.

Джерела фінансування. Ця стаття не отримала фінансової підтримки від державної, громадської або комерційної організації.

\section{Список посилань}

1. Бельський І. В. (2003), Системы эффективной тренировки: Армрестлинг. Бодибилдинг. Бенчпресс: монографія. К. : Мінськ Вида, 531 с.

2. Дворкин Л. С., Новаковский С. В., Степанов С. В. (2003), «Развитие силы юных атлетов в изокинетическом режиме», Физическая культура: воспитание, образование, тренировка. № 4. С. 32-37.

3. Канунова Л. В., Джим В. Ю. (2020), «Визначення кореляційного взаємозв’язку між показниками змагальних і спеціальних вправ», Слобожанський науково-спортивний вісник. № 2 (76). С. 119 - 135.

4. Ніжніченко Д. О. (2013), «Методика корекції тренувального процесу в пауерліфтингу з використанням засобів швидкісносилової спрямованості на етапі попередньої базової підготовки», Слобожанський науково-спортивний вісник. № 2(35), С. 34-38.

5. Николаев П. П., Николаева И. В., Шиховцов Ю. В. (2016), Система подготовки спортсменов в высшей школе: пауэрлифтинг (силовое троеборье): учебное пособие. Самара: Изд-во Самар. гос. экон. ун-та, 112 с.

6. Олешко В. Г. (2011), Підготовка спортсменів у силових видах спорту : навч. посіб. для вузів. Київ, 444 с.

7. Півень О. Б. (2018), Побудова тренувального процесу важкоатлетів 15-17 років з використанням засобів швидкісносилової спрямованості: дис. на здобуття наук. ступеня канд. наук з фіз. виховання і спорту : спец. 24.00.01 «Олімпійський та професійний спорт». Харків, 274 с.

8. Стеценко А. І. (1992), «Про структуру силової підготовки», Пауерліфтинг України. Київ, №1. С.7.

Стаття надійшла до редакції: 24.05.2021 р.

Опубліковано: 23.06.2021 p. 


\title{
СЛОБОЖАНСЬКИЙ НАУКОВО-СПОРТИВНИЙ ВІСНИК
}

\begin{abstract}
Аннотация. Богдан Семко, Вадим Воронецкий, Виктор Джим. Исследование эффективности использования дополнительного оборудования в подготовительном периоде годичного макроцикла спортсменов-пауэрлифтеров высокой квалификации. Цель: исследовать влияние применения дополнительного оборудования, а именно резиновых эспандеров, на развитие силовых показателей пауэрлифтеров высокой квалификации. Материал и методы: в исследование было вовлечено 20 пауэрлифтеров высокой квалификации. Результаты: установлено, что использование дополнительного оборудования в пауэрлифтинге способствует более эффективному развитию силовых качеств спортсменов, а следовательно, ведет к росту спортивных результатов в приседании, жиме лежа и тяге. Использование дополнительного оборудования дает возможность выполнять упражнения с использованием резиновых эспандеров. Резиновые эспандеры фиксируются в силовой раме сверху, после чего растягиваются и крепятся к штанге, за счет растяжения эспандеров спортсмен имеет возможность облегчить подьем в нижней точке. Помощь эспандеров в нижней точке наибольшая, а в верхней точке отсутствует. Данные упражнения рекомендуется атлетам высокой квалификации, при их использовании необходимо четко следить за техникой выполнения упражнений, так как в последних фазах упражнений наблюдается мышечная усталость и техника выполнения упражнения часто нарушается. Спортсмены экспериментальной группы использовали упражнения с резиновым эспандером в подготовительный период по развитию силовых качеств в соревновательных упражнениях: приседания со штангой, жиме лежа, тяге. За период подготовки выполнили 768 подъемов штанги в приседаниях, равный 169 тысяч килограмм, 1020 подъемов штанги в жиме лежа, равной 141 тысяч килограмм, 720 подъемов в тяге, равный 165 тысяч килограмм. За период исследования контрольная и экспериментальная группы увеличили показатели: в приседаниях со штангой (контрольная - 10 кг, экспериментальная - 15 кг; $t$ $=2,82 ; P<0,05)$; жиме лежа (соответственно - $5 \mathrm{kr}, 10 \mathrm{kr} ; t=1,81 ; P>0,05)$ становая тяга (соответственно - 5 кг, 15 кг; $t=1,63 ; P>$ 0,05), что дает более существенное повышение результата экспериментальной группы по отношению к контрольной. Выводы: установлено, что использование данного метода способствует более эффективному развитию силовых показателей, а следовательно, ведет к росту спортивных результатов во всех трех дисциплинах пауэрлифтинга.
\end{abstract}

Ключевые слова: пауэрлифтинг, дополнительное оборудование, приседания, резиновый эспандер.

Abstract. Bogdan Semko, Vadim Voronetsky, Victor Jim. Investigation of the effectiveness of using additional equipment in the preparatory period of the annual macrocycle of highly qualified powerlifters. Purpose: to investigate the influence of the use of additional equipment, namely, rubber bands, on the development of power indicators of highly qualified powerlifters. Material and methods: 20 highly qualified powerlifters were involved in the study. Results: found that the use of additional equipment in powerlifting contributes to a more effective development of athletes' strength qualities, and therefore, leads to an increase in sports results in squatting, bench press and deadlift. The use of additional equipment makes it possible to perform exercises using rubber bands. Rubber bands are fixed in the power frame from above, after which they are stretched and attached to the bar, due to the stretching of the bands, the athlete has the opportunity to facilitate lifting at the lowest point. The help of the expander at the bottom point is the greatest, and at the top point is absent. These exercises are recommended for highly qualified athletes, when using them, it is necessary to closely monitor the technique of performing the exercises, since in the last phases of the exercises muscle fatigue is observed and the technique of performing the exercise is often violated. The sportsmen of the experimental group used exercises with a rubber expander in the preparatory period for the development of strength qualities in competitive exercises: squats with a barbell, bench press, deadlift. During the training period, we performed 768 barbell lifts in squats, equal to 169,000 kilograms, 1020 lifts in the bench press, equal to 141 thousand kilograms, 720 lifts in deadlift, equal to 165,000 kilograms. During the study period, the control and experimental groups increased their indicators: in squatting with a barbell (control - $10 \mathrm{~kg}$, experimental - $15 \mathrm{~kg} ; t=2.82 ; P<0.05$ ); bench press (respectively - $5 \mathrm{~kg}, 10 \mathrm{~kg} ; t=1.81 ; P>0.05$ ) deadlift (respectively $-5 \mathrm{~kg}, 15 \mathrm{~kg} t=1.63 P>0.05$ ), which gives a more significant increase the result of the experimental group on the control. Conclusions: it was found that the use of this method contributes to a more effective development of power indicators, and therefore leads to an increase in sports results in all three disciplines of powerlifting.

Keywords: powerlifting, additional equipment, squats, rubber expander.

\section{References}

1. Bel's'kyy, I. V. (2003), Sistemy effektivnoy trenirovki: Armrestling. Bodibilding. Benchpress [Effective training systems: Arm wrestling. Body-building. Benchpress]: monografнyа. K. : Mrns'k Vida, 531 p. (in Russ.)

2. Dvorkin, L. S., Novakovskiy, S. V., Stepanov, S. V. (2003), "Development of the strength of young athletes in isokinetic mode», Fizicheskaya kul'tura: vospitaniye, obrazovaniye, trenirovka. № 4. pp. 32-37. (in Russ.)

3. Kanunova, L. V., Dzhym, V. YU. (2020), «Determination of the correlation between indicators of competitive and special exercises», Slobozhans'kyy naukovo-sportyvnyy visnyk. № 2 (76). pp. 119 - 135. (in Ukr.)

4. Nizhnichenko, D. O. (2013), «Methods of correction of the training process in powerlifting with the use of speed and strength at the stage of preliminary basic training», Slobozhans'kyy naukovo-sportyvnyy visnyk. № 2(35), pp. 34-38. (in Ukr.)

5. Nikolayev, P. P., Nikolayeva, I. V., Shikhovtsov, YU. V. (2016), Sistema podgotovki sportsmenov v vysshey shkole: pauerlifting (silovoye troyebor'ye) [The system of training athletes in higher education: powerlifting (powerlifting)]: uchebnoye posobiye. Samara: Izd-vo Samar. gos. ekon. un-ta, 112 p. (in Russ.)

6. Oleshko, V. H. (2011), Pidhotovka sportsmeniv u sylovykh vydakh sportu [Training of athletes in power sports:]: navch. posib. dlya vuziv. Kyyiv, 444 p. (in Ukr.)

7. Piven', O. B. (2018), Pobudova trenuval'noho protsesu vazhkoatletiv 15-17 rokiv z vykorystannyam zasobiv shvydkisno-sylovoyi spryamovanosti [Construction of the training process of weightlifters 15-17 years using the means of speed-power orientation]: dys. na zdobuttya nauk. stupenya kand. nauk z fiz. vykhovannya i sportu : spets. 24.00 .01 «Olimpiys'kyy ta profesiynyy sport». Kharkiv, 274 p. (in Ukr.)

8. Stetsenko, A. I. (1992), «On the structure of strength training», Pauerliftynh Ukrayiny. Kyyiv, №1. p.7. (in Ukr.)

Received: 24.05.2021.

Published: 23.06.2021. 
Відомості про авторів / Information about the Authors

Семко Богдан Тарасович: аспірант; Харківська державна академія фізичної культури: вул. Клочківська 99, м. Харків, 61058, Україна.

Семко Богдан Тарасович: аспирант; Харьковская государственная академия физической культуры: ул. Клочковская 99, г. Харьков, 61058, Украина.

Bogdan Semko: graduate student; Kharkiv State Academy of Physical Culture; Klochkivska str. 99, Kharkiv, 61058, Ukraine.

ORCID: https://orcid.org/0000-0003-4125-2274

E-mail: semko199309@gmail.com

Воронецький Вадим Борисович: к.пед.н.; Кам'янець-Подільський національний університет імені Івана Огієнка: вулиця Огієнка, 61, м. Кам'янець-Подільський, Хмельницька область, 32301.

Воронецкий Вадим Борисович: к.пед.н.; Каменец-Подольский национальный университет имени Ивана Огиенко: улица Огиенко, 61, г. Каменец-Подольский, Хмельницкая область, 32301.

Vadim Voronetsky: PhD (Pedagogical Sciences); Ivan Ogienko Kamyanets-Podilsky National University: 61 Ogienko Street, Kamyanets-Podilsky, Khmelnytsky Region, 32301.

ORCID: https://orcid.org/0000-0002-7206-8157

E-mail: semko199309@icloud.com

Джим Віктор Юрійович: к.фіз.вих., доцент; Харківська державна академія фізичної культури: вул. Клочківська 99 , м. Харків, 61058, Україна. Джим Виктор Юрьевич: к.физ.восп., доцент; Харьковская государственная академия физической культуры: ул. Клочковская 99, г. Харьков, 61058, Украина.

Victor Jim: PhD (Physical Education and Sport), Associate Professor; Kharkiv State Academy of Physical Culture: Klochkivska 99, Kharkiv, 61058, Ukraine.

ORCID: https://orcid.org/0000-0002-4869-4844

E-mail: djimvictor@gmail.com 